\title{
Demystifying Septoplasty in Children
}

\author{
Mariane Barreto Brandão Martins ${ }^{1}$ Rosa Grazielle de Lima ${ }^{1}$ Francis Vinícius Fontes de Lima ${ }^{1}$ \\ Valéria Maria Prado Barreto ${ }^{2}$ Arlete Cristina Granizo Santos ${ }^{3}$ Ronaldo Carvalho Santos Júnior 4
}

${ }^{1}$ Department of Otorhinolaryngology, University Hospital, Faculty of medicine, Universidade Federal de Sergipe, São Cristóvão, SE, Brazil

Address for correspondence Mariane Barreto Brandão Martins, Resident Doctor, Hospital Universitário da Universidade Federal de

${ }^{2}$ Department of Otolaryngology, Universidade Fedreral de Sergipe, Sergipe, Rua Deputado Antônio Torres, 699, Bairro Pereira Lobo, CEP São Cristóvão, SE, Brazil

${ }^{3}$ Department of Otolaryngology, University Hospital of Universidade 49052050, Brazil (e-mail: mari.ane_martins@yahoo.com.br).

Federal de Sergipe, São Cristóvão, SE, Brazil

${ }^{4}$ Department of Otolaryngology, Universidade de São Paulo, São Paulo, SP, Brazil; University Hospital of Universidade Federal de Sergipe, São Cristóvão, SE, Brazil

Int Arch Otorhinolaryngol 2014;18:54-56.

\begin{abstract}
Keywords

- nasal septum

- face

- growth and development

Introduction Septum deviation in children may alter the early physiologic process of breathing, causing obligatory oral breathing and consequently changing craniofacial development and even intellect. Because of these consequences, septoplasty should be performed as early as possible.

Materials and Methods The retrospective study reviewed the results of septoplasty in 40 children under 12 years old who had follow-up after surgery for a maximum period of 7 years. The research was submitted to the ethics committee and approved with protocol number 10331912.0.0000.0058.

Results Forty patients underwent septoplasty, 39 (97.5\%) had cauterization of inferior turbinate and associated procedure, 20 (50\%) had adenotonsillectomy, and 17 (42.5\%) had adenoidectomy.

Conclusion Nasal septum deviation should be corrected early to provide the harmonious growth of the face and to enable normal development of the child, without the occurrence of nasal deformity.
\end{abstract}

\section{Introduction}

Septoplasty in adults is a well-established surgery, but in children it is still a matter of controversy. Some authors contraindicate surgery before 17 to 18 years of age, because they think that early surgical intervention would influence the normal growth of the nose; others indicate surgery based on the explanation that the sooner septal deviation of a child is corrected, the greater chance of developing normal breath and therefore a suitable facial growth., ${ }^{1,2}$ The surgery has undergone technical changes since its introduction to minimize trauma to the nasal structure, thus reducing the possible postoperative complications. ${ }^{1}$ This study aims to present the experience of the Depart- ment of Otolaryngology, University Hospital, in the surgical treatment of children with nasal septum deviation and debunk the concept that septoplasty should only be performed after 17 to 18 years of age.

\section{Materials and Methods}

This longitudinal cohort study had a sample of 40 patients, 24 (60\%) boys and $16(40 \%)$ girls, aged 4 to 12 years, with a mean age of 9 years, in the period from January 2005 to March 2012 (-Table 1). Patients underwent septoplasty and associated procedures such as adenoidectomy, tonsillectomy, and cauterization of inferior turbinate, when indicated, in the same surgery. These were assessed clinically and through nasal received

March 17, 2013

accepted

August 11, 2013
DOI http://dx.doi.org/

10.1055/s-0033-1358576. ISSN 1809-9777.
Copyright $(2014$ by Thieme Publicações License terms Ltda, Rio de Janeiro, Brazil 
Demystifying Septoplasty in Children Martins et al. 55

Table 1 Patient characteristics $(n=40)$

\begin{tabular}{|l|l|}
\hline & $n(\%)$ \\
\hline Sex & \\
Female & $16(40 \%)$ \\
Male & $24(60 \%)$ \\
Age at surgery $(y)$ & \\
4 & $3(7.5 \%)$ \\
5 & $1(2.5 \%)$ \\
6 & $5(12.5 \%)$ \\
7 & $1(2.5 \%)$ \\
8 & $4(10 \%)$ \\
9 & $5(12.5 \%)$ \\
10 & $5(12.5 \%)$ \\
11 & $10(25 \%)$ \\
\hline 12 & $6(15 \%)$ \\
\hline
\end{tabular}

endoscopy in the postoperative period at 10,30 , and 60 days, and annually thereafter, with the longest follow-up of 7 years.

\section{Surgical Technique}

1. With the patient under general anesthesia, asepsis and antisepsis procedures are performed.

2. Initially, a topically sterile cotton ball soaked in adrenaline concentration of $1: 2,000$ is placed in both nostrils with the aim of promoting vasoconstriction. After this, epinephrine solution is infiltrated at a concentration of $1: 80,000$ in the septal mucosa of both nostrils.

3. A septal incision is performed on the left side, held at the mucocutaneous transition at nasal vestibule.

4. The septal mucosa is detached in subperichondrial and subperiosteal bilaterally after transfixation of the quadrangular cartilage.

5. Detachment is extended to the nasal floor bilaterally to facilitate the removal of possible cartilaginous and bony deviations.

6. Cartilaginous and bony deviations are excised conservatively to preserve the growth of the septal cartilage, thereby avoiding abnormalities in nasal growth.

7. Hemostasis is reviewed.

8. The initial incision is sutured.

9. Splints and nasal packing are not used at the end of surgery.

10. All steps are performed with the endoscope at 0 degrees.

\section{Results}

Forty patients underwent septoplasty; 39 (97.5\%) of them had associated inferior turbinate cauterization procedure, 20 (50\%) patients had adenotonsillectomy, and 17 (42.5\%) adenoidectomy (-Table $\mathbf{2}$ ).

There were no intraoperative complications in any of the operated cases. All patients were evaluated by performing nasal dressings in 10,30 , and 60 days, observing possible adhesions and recurrence of the deviation, septal perforation, infection, and nasal deformity. After this period, annual follow-up was done with the maximum of 7 years.

None of the aforementioned complications were recorded during this monitoring period.
Table 2 List of associated procedures

\begin{tabular}{|l|l|}
\hline & $n(\%)$ \\
\hline Septoplasty & $40(100 \%)$ \\
\hline Adenoidectomy & $17(42.5 \%)$ \\
\hline Adenotonsillectomy & $20(50 \%)$ \\
\hline Cauterization of nasal inferior turbinates & $39(97.5 \%)$ \\
\hline
\end{tabular}

\section{Discussion}

There is controversy in the literature about the consequences of septoplasty for septal deviation in children, and some studies have shown that when done early the procedure brought benefits in the short and long term. ${ }^{2}$ A study conducted with 80 patients aged between 4 and 14 years old who underwent septoplasty (65 patients), rhinoplasty (11 patients), and rhinoplasty (4 patients) showed postoperative complications in only 13 of these patients (not specifying the surgery performed); the authors concluded that the benefits brought by these surgeries outweigh the occurrence of these minimal complications. ${ }^{2}$ Dispenza et $\mathrm{al}^{3}$ stated that more important than the age of indication for the procedure is the degree of nasal obstruction, placing it as an absolute indication, because nasal obstruction during infancy disrupts the normal development of the angle of the skull base and consequently the maxillofacial growth and may cause malocclusion and jaw protrusion with bone deformities, confirmed even with anthropometric measurements. Others $^{4-7}$ also claimed that delay defect correction can bring negative effect on organ systems that play a role in somatic and psychic development of the child including voice changes and sleep disturbances, but speculated that in some situations monitoring should be done for real indication for surgical treatment. A study performed with 44 patients aged between 8 and 12 years old who underwent septal surgery (reconstructive rhinoplasty) showed efficacy in relation to nasal obstruction and demonstrated that surgery when performed conservatively does not harm the facial growth or promote nasal deformities. $^{8}$ In our study, all 40 patients were younger than 12 years old and underwent septoplasty surgery early, avoiding development of deformities resulting from mouth breathing. None of our patients had facial deformity at the first visit and none had nasal deformity after surgery (maximum follow-up of 7 years).

Septoplasty can be performed safely without affecting the nasal and facial development in appropriately selected patients, and delaying the procedure may cause asymmetry and craniofacial anomalies. ${ }^{9,10}$ There are caveats, however, that surgery can negatively influence the growth of the nasal dorsum when done by an external approach and that before considering pediatric nasal septum surgery, a thorough clinical examination should be performed for a correct diagnosis and appropriate surgical indication. ${ }^{9}$

Research that showed convincingly that septoplasty in children causes nasal deformity could not be found in the 
literature. Some studies even questioned the possibility of the occurrence of these deformities; however, most studies, like ours, showed that early surgery when indicated is beneficial.

Thus, the studies found in the literature, ${ }^{1-10}$ whether anthropometric or clinical trials, corroborated our findings that septoplasty in children allows appropriate craniofacial growth and development, prevents abnormalities in somatic and psychic component of the patient, as well as demystifies the concept that septoplasty should only be performed after the age of 17 to 18 years old.

\section{Conclusion}

The nasal septum deviation should be corrected early to provide a harmonious craniofacial growth and appropriate child development, without the occurrence of nasal deformity.

\section{References}

1 Patrocíno JA. Septoplastia em crianças. Rev Bras Otorrinolaringol (Engl Ed) 1999;65(4):302-306
2 Maniglia JV, Molina FD, Maniglia LP, et al. Rinosseptoplastia em crianças. Rev Bras Otorrinolaringol (Engl Ed) 2002;68(3):320-323

3 Dispenza F, Saraniti C, Sciandra D, Kulamarva G, Dispenza C. Management of naso-septal deformity in childhood: long-term results. Auris Nasus Larynx 2009;36(6):665-670

4 Verwoerd CDA, Verwoerd-Verhoef HL. [Rhinosurgery in children: developmental and surgical aspects of the growing nose]. Laryngorhinootologie 2010;89(1, Suppl 1):S46-S71

5 Verwoerd CDA, Verwoerd-Verhoef HL. Rhinosurgery in children: basic concepts. Facial Plast Surg 2007;23(4):219-230

6 Cupero TM, Middleton CE, Silva AB. Effects of functional septoplasty on the facial growth of ferrets. Arch Otolaryngol Head Neck Surg 2001;127(11):1367-1369

7 Christophel JJ, Gross CW. Pediatric septoplasty. Otolaryngol Clin North Am 2009;42(2):287-294, ix

8 Ortiz-Monasterio F, Olmedo A. Corrective rhinoplasty before puberty: a long-term follow-up. Plast Reconstr Surg 1981;68(3): 381-391

9 Lawrence R. Pediatric septoplasy: a review of the literature. Int J Pediatr Otorhinolaryngol 2012;76(8):1078-1081

10 D’Ascanio L, Lancione C, Pompa G, Rebuffini E, Mansi N, Manzini M. Craniofacial growth in children with nasal septum deviation: a cephalometric comparative study. Int J Pediatr Otorhinolaryngol 2010;74(10):1180-1183 